\title{
A small membrane stabilising protein critical to the pathogenicity of Staphylococcus aureus.
}

Seána Duggan ${ }^{1 \#}$, Maisem Laabei ${ }^{2 \#}$, Alaa Alnahari ${ }^{1}$, Eóin C. O’Brien ${ }^{3}$, Keenan A. Lacey ${ }^{3 \$}$, Leann Bacon $^{1}$, Kate Heesom ${ }^{4}$, Chih-Lung Fu ${ }^{5}$, Michael Otto ${ }^{5}$, Eric Skaar ${ }^{6}$, Rachel M. McLoughlin ${ }^{3}$ and Ruth C. Massey ${ }^{1 *}$

The authors have withdrawn this manuscript while substantial changes are being made to its content and format. Following submission to biorxiv an alternative hypothesis to explain the data has come to light, and the authors would like to perform some additional experimentation to test this. Therefore, the authors do not wish this work to be cited as reference for the project. If you have any questions, please contact the corresponding author. 